\title{
The art of targeting gut microbiota for tackling human obesity
}

\author{
Marisol Aguirre ${ }^{1,2,3} \cdot$ Koen Venema ${ }^{1,4}$
}

Received: 25 March 2015/Accepted: 11 May 2015/Published online: 20 May 2015

(C) Springer-Verlag Berlin Heidelberg 2015

\begin{abstract}
Recently, a great deal of interest has been expressed regarding strategies to tackle worldwide obesity because of its accelerated wide spread accompanied with numerous negative effects on health and high costs. Obesity has been traditionally associated with an imbalance in energy consumed when compared to energy expenditure. However, growing evidence suggests a less simplistic event in which gut microbiota plays a key role. Obesity, in terms of microbiota, is a complicated disequilibrium that presents many unclear complications. Despite this, there is special interest in characterizing compositionally and functionally the obese gut microbiota with the help of in vitro, animal and human studies. Considering the gut microbiota as a factor contributing to human obesity represents a tool of great therapeutic potential. This paper reviews the use of antimicrobials, probiotics, fecal microbial therapy, prebiotics and diet to manipulate obesity through the human gut microbiota and reveals inconsistencies and implications for future study.
\end{abstract}

Koen Venema

koen.venema@outlook.com

1 Top Institute of Food and Nutrition, PO Box 557, 6700 AA Wageningen, The Netherlands

2 Department of Human Biology, Faculty of Health, Medicine and Life Sciences, School of Nutritional and Translational Research in Metabolism (NUTRIM), Maastricht University, PO Box 616, 6200 MD Maastricht, The Netherlands

3 The Netherlands Organization for Applied Scientific Research (TNO), PO Box 360, 3700 AJ Zeist, The Netherlands

4 Beneficial Microbes Consultancy, Johan Karschstraat 3, 6709 TN Wageningen, The Netherlands
Keywords Obesity $\cdot$ Gut microbiota $\cdot$ Fecal transplantation · Probiotics · Prebiotics · Diet

\section{Introduction}

The human gut can be considered a bioreactor that harbors a complex ecosystem of microbes, collectively termed the microbiota, which is estimated to include at least $10^{14}$ cells ml ${ }^{-1}$ (Backhed et al. 2004). Nearly $1.5 \mathrm{~kg}$ of bacteria reside in the human gut (Nicholson et al. 2005), and approximately $50 \%$ of the wet weight of fecal biomass in humans is estimated to come from bacterial cells (Zhao 2013). The identification and analysis of the metabolic capacity and phylogeny from these gut microbial communities unfold specific characteristics in healthy and unhealthy subjects (Ramakrishna 2013; Aguirre et al. 2014). Therefore, it has been possible to propose a potential causative role for the microbiota in several types of disorders (Faith et al. 2014).

Interestingly, increasing evidence suggests that the gut microbiota plays an important role in human obesity (Harris et al. 2012; Aguirre et al. 2014; Guida and Venema 2015). Several important discoveries have been made from which we highlight: (i) the impact of dietary components on the composition of gut microbiota. It has been estimated that as much as approximately $57 \%$ of the total structure (i.e., composition) of the gut microbiota could be explained by dietary changes, while some $12 \%$ could be attributed to host genetics (Zhang et al. 2010). (ii) the effects of gut microbiota composition and activity on mucosal and systemic immune responses and energy metabolism (Requena et al. 2013). Obesity is generally accepted as a state of chronic, low-grade inflammation (Guida and Venema 2015). Findings suggest that the increase in the uptake of lipopolysaccharide 
(LPS), a molecule released by Gram-negative bacteria in the gut, and the permeability of the intestine induce a systemic inflammation (Requena et al. 2013). Furthermore, commensal mucosal bacteria interacting with the mucus layer may also have an effect on obesity as shown by Everard et al. (2013) who inversely correlated the abundance of $A$. muciniphila and obesity. Last but not least, it has been found that metabolites produced from the fermentation of indigestible dietary compounds serve as energy source to the host ("energy harvest" hypothesis) and they have been proposed to mediate (indirectly) the release of satiety hormones (Guida and Venema 2015).

The analysis of mice and human gut microbiota over time during weight loss or weight gain has revealed interesting dynamics. In mice and in vitro models, the effect of diet on the microbiota seems to be more straightforward than in humans due to a better control of variables (e.g., genetics, diet, environmental factors). In humans, a high variance in the results is observed, and it might be that diet could affect and modify the microbiota but in a way that is depending on the existing microbiota of the individual.

Due to the conflicting pieces of evidence from in vitro data, animal models and human interventions, it is important to understand and reduce the inconsistencies in the current scientific data. Still, already studies investigating the influence of diet on microbes and optimal health have emerged as a potential therapeutic treatment to tackle obesity.

There are many promising strategies to manipulate the gut microbiota (Fig. 1). In this review, we highlight the use of antimicrobials, probiotics, fecal microbial therapy, pre- biotics and diet with a focus on these interventions in tackling human obesity.

\section{Strategies to manipulate gut microbiota in obesity}

\section{Antibiotics}

Antibiotic treatment constitutes one important factor that disturbs microbiota composition (Moreno-Indias et al. 2014). Due to their broad-spectrum activity, antibiotics can also target nonpathogenic and even beneficial populations in the gut, thereby disrupting important interactions with the host (Chen et al. 2014). However, evidence about the consequences of antibiotic use on obesity is controversial, as it has raised suggestions of both promoting and preventing obesity.

Antibiotics have been used in animals as growth-promoting agents with the aim of increasing their size and weight. Strikingly, such effects have not been observed with antivirals or antifungals (Butaye et al. 2003; Dibner and Richards 2005; Cho et al. 2012). The weight gain effects from antibiotics observed in animals have been suggested to also potentially occur in humans. For instance, the different groups of bacteria which have been affected after antibiotic consumption may take several months to recover (Jernberg et al. 2010; Dethlefsen and Relman 2011). Therefore, it has been suggested that antibiotic therapy (at therapeutic doses) in early life can dramatically affect the evolution of infant gut microbiota (Fouhy et al. 2012), making these treated children prone to develop obesity, due to a dysbiosis of their gut microbiota.
Fig. 1 Different strategies to manipulate the gut microbiota

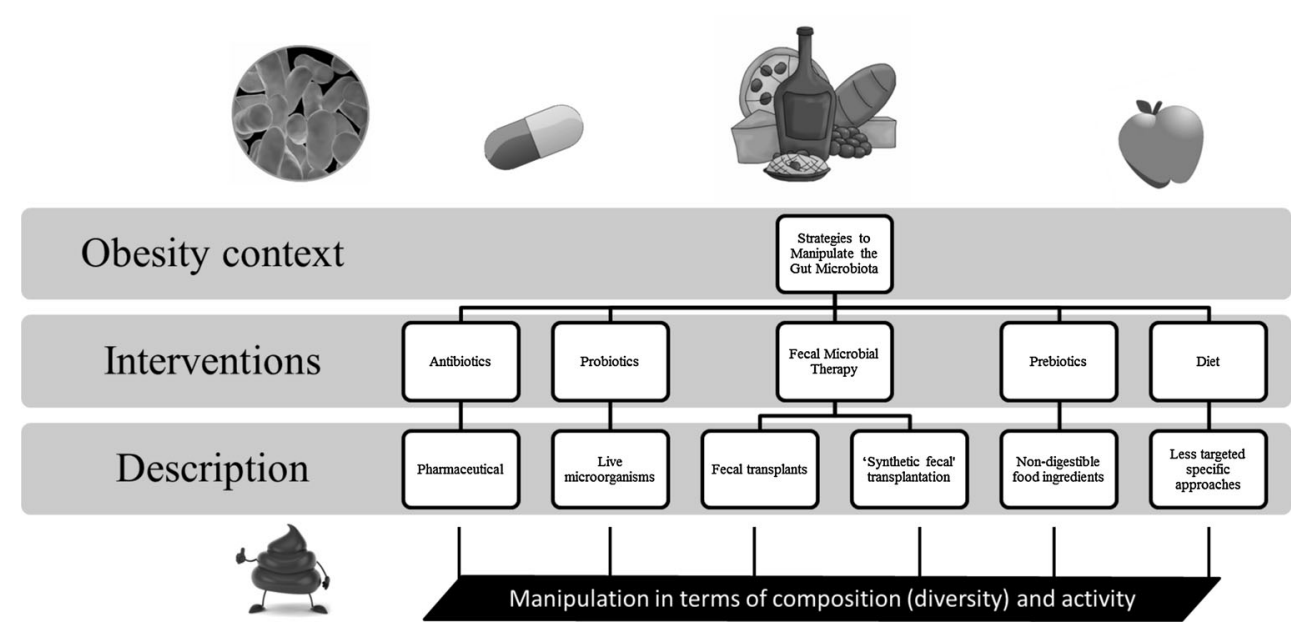


Rosenberg et al. (1974) reviewed the effects of using oxytetracycline and chlortetracycline from studies involving over 900 infants and children with a long-term use (as long as 3 years) from 1952 to 1963 . The authors observed that children under antibiotic treatment showed an increase in height and weight gain. Most recent studies also agree with the link between obesity in infants and their early exposure to antibiotics. Bailey et al. (2014) associated the exposure of antibiotics during infancy with early childhood obesity in a cohort study spanning 2001-2013 health records comprising 64.580 children. Another study, determining the impact of antibiotic therapy on BMI changes in adults with infective endocarditis (IE), observed that vancomycin- and gentamycin-treated patients increased significantly in their BMI values, while other patients treated with other antibiotics did not (Thuny et al. 2010). A major effect was observed in male patients who did not have cardiac surgery and were older than 65 since they, indeed, developed obesity.

Antibiotic treatment has also been indicated to prevent obesity, by improving glucose tolerance and improving endotoxemia (Cani et al. 2008; Membrez et al. 2008). Evidence in mice suggests that antibiotic therapy has a considerable impact on adiposity and plasma LPS levels, oxidative stress, macrophage infiltration in adipose tissue, inflammation and metabolic disorders (Cani et al. 2008; Bech-Nielsen et al. 2012). Such effects could have implications in type 2 diabetes, low-grade inflammation and obesity. In addition, the decrease or delay in the onset of diabetes has also been observed in an antibiotic treatment combined with a hydrolyzed casein diet in rats (Brugman et al. 2006). These findings underscore the implications of antibiotics in obesity which have brought the controversial speculation by experts that obesity could be reversed in infants from families with this problem by following an early life specific antibiotic treatment to manipulate the obesogenic bacteria transferred from the mother during delivery (Jess 2014).

The exact mechanisms by which antibiotics may promote or counteract weight gain are not clearly understood (Moreno-Indias et al. 2014). Still, at present, the main hypotheses are as follows:

(i) Perturbation of the intestinal barrier: the disruption of the integrity of the intestinal barrier which promotes an increased inflammatory tone of the gut (Wlodarska et al. 2011). As previously studied, obesity may also be associated with gut inflammation (Hotamisligil 2006; de La Serre et al. 2010);

(ii) Alteration of the microbial activity and metabolism: competing microorganisms are reduced which may spare nutrients and leave them for the host (Feighner and Dashkevicz 1987). Furthermore, there is possibly an attenuated production of important metabolites such as short-chain fatty acids (SCFA) as well as differences in the capacity to metabolize and transport vitamins, bile acid, hormones and cholesterol (Perez-Cobas et al. 2013; Chen et al. 2014). In case of a lower production of SCFA, there is no longer an extra input of energy to the host in the form of the acids, which act as an energy source for the gut epithelium and are involved in gluco- and liponeogenesis. An increased production of SCFA is thought to be characteristic from the obese microbiome (Fava et al. 2013). In addition, it has been suggested that antibiotic uptake may interfere with sugar anabolic capacity of the microbiota by altering the enzymes controlling consistency, composition and thickness of mucin glycans (Hernandez et al. 2013). An attenuated production of growth depressing toxins has also been proposed (Feighner and Dashkevicz 1987);

(iii) Weakening of the innate immunity: as a consequence of antibiotic use, the low diversity induced in the microbiota can decrease the amount of receptors of microorganism-associated molecular patterns (MAMP) (Dessein et al. 2009; Wells et al. 2010). In addition, the dysregulation in the secretion of cytokines related to pro-inflammatory processes reduces the regulation of $\mathrm{T}$ cell differentiation and activation (Ivanov et al. 2009). The effect of weakening the innate immunity, at a certain degree, may demand less energy from the host stimulating weight gain (Williams et al. 1997).

However, generalization of the effect of antibiotics in human obesity has to be carefully done. To begin with, an important issue to consider is that a large number of clinical studies are focused on compositional and diversity analysis of the effects of antibiotic on gut microbiota (Moreno-Indias et al. 2014). This makes it difficult to critically evaluate whether an improvement in metabolic derangements actually occurs in humans as indicated from studies in animals (Moreno-Indias et al. 2014). In addition, response to antibiotic treatment varies among individuals and it has been suggested that indirect factors play a role, such as antibiotic-resistant genes in the microbial community, route of administration (orally or intravenous administrated) and/or dosage (Dethlefsen et al. 2008; Falagas and Karageorgopoulos 2010; Bifulco 2014). The use of antimicrobials has been suggested to be accompanied by an adjustment of dose dependent on composition and body 
size in adults (Falagas and Karageorgopoulos 2010). For instance, altered physiological factors commonly found in obese subjects including metabolism, protein binding and clearance of antimicrobial agents can potentially affect pharmacokinetics of drugs, including antibiotics (Pai and Bearden 2007; Falagas and Karageorgopoulos 2010). Hydrophilic antibiotics may present a high distribution in obese subjects, but they have a lower capacity to dissolve in adipose tissue (Falagas and Karageorgopoulos 2010). In fact, differences in absorption of drugs in the gastrointestinal tract are still not clear among subjects differing in weight (Polotsky and Polotsky 2010). Finally, it is important to consider time of exposure to antibiotics. After shortterm antibiotic therapy, the gut microbiota can recover. However, permanent alterations have been suggested after long-term treatment (Robinson and Young 2010). For instance, it has been proposed that antibiotics may lead to the complete elimination of specific bacteria in some individuals (Bartosch et al. 2004; Savino et al. 2011).

\section{Probiotics}

Probiotics are defined as "live microorganisms which, when consumed in adequate amounts, confer a health effect on the host" by the World Health Organization and the Food and Agriculture Organization of the United Nations (Morelli and Capurso 2012).

Evidence about the "anti-obesity" effects of probiotics mainly comes from research performed in rodents and the administration of the genus Lactobacillus (Druart et al. 2014). This is striking, given the positive correlations that have been found between the presence of lactobacilli and obesity by some (Armougom et al. 2009; Million et al. 2012).

Lactobacillus gasseri BNR17 feeding showed a fat mass gain but body weight suppression in obese rodents following a high-sucrose diet (Yun et al. 2009; Kang et al. 2010, 2013; Druart et al. 2014). Some other studies have focused on the use of Bifidobacterium strains to evaluate the effects of probiotics and their potential antiobesity effect (Druart et al. 2014). Such studies used specifically $B$. adolescentis or B. longum or a combination including mainly B. longum SPM1207-SPM1205 and B. pseudocatenulatum SPM1204 (An et al. 2011; Chen et al. 2011, 2012; Druart et al. 2014).

A few interventions have evaluated the effect of probiotics on weight modulation in humans. For instance, $L$. rhamnosus GG (ATCC 53103) and Bifidobacterium lactis Bb12 along with dietary counseling were found to influence maternal anthropometric measurements during and after pregnancy (Ilmonen et al. 2011). The reduction in these measurements was also observed in overweight adults after 12 weeks of intervention with $L$. gasseri SBT2055 (Kadooka et al. 2010). In addition, the perinatal use of L. rhamnosus GG was demonstrated to inhibit excessive weight gain in children during the first years of life (Luoto et al. 2010).

The administration of probiotics also indicates their effect on counteracting certain metabolic diseases associated with obesity (Druart et al. 2014). For instance, Hamad et al. (2009) examined the potential impact of milk fermented with L. gasseri SBT2055 on adiposity parameters in obese and lean Zucker rats. Obese Zucker rats present a mutation in the leptin receptor gene which stimulates over-eating in these animals leading to obesity (Chua et al. 1996). The study revealed that obese animals did not present a significant alteration in serum leptin concentrations, contrary to the lean rats which decreased nearly $36 \%$. Yet, levels of total and HDL cholesterol were significantly reduced in obese rats, while adiponectin and glucose were not altered in any of the groups. The study provides an indication about the reduction in adipocyte hyperthrophy and visceral adipose tissue mass. Still, the authors could not clearly attribute to the probiotic strain alone, as they might have occurred from its milk fermentation products as well.

Despite the interesting results, there is some controversy regarding the consumption of probiotics and their role in obesity (Raoult 2009; Clarke et al. 2012) as eluded to above. Supplementation with probiotics has been suggested as a therapy for inducing weight gain in subjects suffering from severe acute malnutrition (Solis et al. 2002; Kerac et al. 2009; Angelakis et al. 2013). Furthermore, Raoult suggests to be cautious with the consumption of probiotics previously used as growth promoters in the animal food industry and that there is a need to fully study such products in order to confirm how safe they are for human use (Raoult 2009). Such views have been criticized by other scientists either rejecting the supporting data cited in their opinion by considering it not representative or not showing a significant impact on weight gain in the subjects studied (Delzenne and Reid 2009; Ehrlich 2009; Clarke et al. 2012). Moreover, effects of probiotics are strain specific, so there may very well be strains that have an anti-obesogenic property.

Further studies on the effect of probiotics in human obesity need to address:

(i) A deep analysis of the gut microbiota after the ingestion of the probiotic tested since there is little evidence evaluating whether the selected probiotic bacteria are, in fact, directly responsible for the improvement in metabolic disorders including obesity (Druart et al. 2014). For instance, a study investigating the effect of the supplementation of 
L. acidophilus NCDC13 increased Bifidobacterium spp in the gut microbiota (Arora et al. 2012);

(ii) Their modulation of the production of bacterial metabolites in order to propose a clear mechanism underlying correlations with obesity (Druart et al. 2014);

(iii) Time of treatment and dosage, since some studies suggest that failing in showing the effect of probiotics in patients with metabolic syndrome is due to a short duration and/or under-dosing of the strain (Leber et al. 2012; Tripolt et al. 2013);

(iv) The likelihood that related probiotic strains differ in their phenotype and genotype and therefore their probiotic effect (Klaenhammer et al. 2008). Therefore, comparisons between strains in order to critically evaluate the specific ability of certain probiotic strains in the modulation of obesity have been suggested (Druart et al. 2014).

\section{Fecal microbial therapy}

Fecal matter has been traditionally considered a waste. Yet, the potential of fecal microbial therapies demonstrates the value of a fecal donation (Allen-Vercoe et al. 2012). Currently, there are two innovative and noninvasive ways of fecal microbial therapy with a promising future in treating or preventing obesity: fecal microbiota transplantation (FMT) and "synthetic fecal" transplantation (SFT).

FMT has been suggested to potentially re-establish the healthy microbiota in the recipient and to preserve around 1150 functional bacterial species transferred by the healthy donor (Qin et al. 2010; Zhang et al. 2012). As explained by Zhang et al. (2012), the practice of FMT is not new, since evidence indicates the use of human fecal slurries in patients suffering from severe diarrhea or food poisoning by Ge Hong, a well-known traditional doctor during the fourth century in China. Such treatment was considered as a medical miracle due to the improvement in the critical conditions of the patients. However, there is a lack of literature about the use of FMT to potentially treat or prevent obesity.

In FMT, a fecal suspension from a donor is administrated to a recipient (Borody et al. 2014). Various methods of installation are used for FMT which include upper tract endoscopy, nasogastric tube retention enema, colonoscopy and a nasojejunal tube (Gough et al. 2011; Postigo and Kim 2012). Nevertheless, it has been suggested that the best route for administration should be determined based on the anatomic location of the disease (Smits et al. 2013).

FMT has been used in patients with severe Clostridium difficile infection (CDI), relapsing CDI or CDI in inflammatory bowel disease (IBD) (Smits et al. 2013). Regardless of the route of installation, it has been observed that a success rate of 76-92\% can be achieved (Bakken 2009; van Nood et al. 2009; Gough et al. 2011). Some studies report the use of FMT in patients with irritable bowel syndrome (Borody et al. 1989, 2004; Smits et al. 2013), autoimmune diseases (Borody et al. 2014) and metabolic diseases (Vrieze et al. 2012). In regard to metabolic diseases, Vrieze et al. (2012) observed that after the infusion of microbiota from lean human donors to obese recipients, the insulin sensitivity from the recipients improved. The authors indicated that probably such improvement is due to the increment in the production of butyrate by the colonic bacteria. The transplantation procedure in this case was performed in the duodenal region which was suggested to be effective and safe for treating metabolic disorders (Vrieze et al. 2012).

Major concerns regarding FMT include the absence of safety measures, the lack of a standardized treatment regime and the potential encouragement of patients to try the treatment at home without medical supervision (Silverman et al. 2010; El-Matary et al. 2012; Petrof et al. 2013b). Furthermore, there is no consensus regarding screening tests for donors with respect to carriage of pathogens or diseases, which constitutes a drawback of the technique. There is an imminent risk in transmitting unknown bacteria that are considered commensal, but with the potential to induce disease, such as certain groups associated with colorectal cancer or unknown pathogens which may also represent a threat if the recipient is immuno-compromised (Allen-Vercoe et al. 2012; El-Matary et al. 2012; Petrof et al. 2013a). In addition, there is the possibility that FMT has beneficial effects only from specific donors (e.g., superdonors) (Nieuwdorp et al. 2014). Therefore, further studies are needed to evaluate their potential in treating or preventing obesity. Moreover, even in the trial of Vrieze et al. (2012), there were people who were nonresponders, either due to their own physiological state or due to the fact that they received a sample from a donor that was not efficacious. Since we do not know what an efficacious microbiota looks like, these issues will unlikely be resolved in the near future.

The other fecal microbial therapy constitutes the use of a SFT. In this technique, well-characterized strains derived and cultured from a fecal donation from a healthy individual are transplanted to a recipient (Allen-Vercoe et al. 2012). The strains are grown in cultures (defined mixtures that aim to be representative to a native fecal microbiota) and are administered in a suspension to the recipient (Allen-Vercoe et al. 2012; Petrof et al. 2013a). This type of fecal substitute has shown to be a feasible and effective alternative to the use of the transplantation of feces from a donor (Petrof et al. 2013b), which seems to overcome the limitations from FMT in terms of transmission of a donor's 
infection and patient acceptance. As explained by Petrof et al. (2013b), the benefits from using a synthetic transplant over a conventional transplant are that the composition of the mix of bacteria to be transplanted is known which guarantees: (i) an enhanced safety profile: the reduced contamination of potential pathogens including viruses, while the bacteria included are selected based on their sensitivity to antimicrobials; (ii) reproducibility: the preparation could be replicated in case of future treatment in a chemostat allowing the species to grow in a continuous culture under conditions resembling to the gut without affecting its stability (Allen-Vercoe et al. 2012; Petrof et al. 2013b). The pilot study from Petrof et al. (2013b) in which they evaluated the use of a synthetic stool comprising 33 isolates recovered from the fecal sample from a healthy donor seems promising for the treatment of CDI. Interestingly, the authors also observed that the transplanted bacteria seemed to stably colonize the colon which offers an advantage over the consumption of probiotics due to their transient effect. However, conclusions about the potential effects of SFT cannot be easily drawn from the study due to the small patient population studied $(n=2)$. Therefore, rigorous clinical trials are also needed to study the utility, effectiveness and safety of SFT (Allen-Vercoe et al. 2012), as well as its potential as a therapy for obesity. Furthermore, a perceived difficulty of this technique comes from the experience that the microbial ecosystem from the human gut is difficult to culture. Yet, Petrof et al. (2013a) allude to recent technological advances to make progress in this area.

\section{Prebiotics}

The so-called Western diet is characterized by an unbalanced high content of refined carbohydrates when compared to other diets from the early human history, or those typical for developing countries (Scott et al. 2008). The potential of prebiotics to reduce food intake, fat mass development and body weight was demonstrated more than 10 years ago by changing the gut microbiota (with prebiotics such as inulin and oligofructose) and the cross-talk between the brain and gut microbiota (Cani et al. 2004, 2005; Delzenne et al. 2005). Therefore, the future of prebiotics use to decrease the incidence and morbidity of obesity in humans is an interesting field to explore. For instance, the analysis of the gut microbiota from two healthy individuals reflected a microbial community enriched in many clusters that represent key genes involved in the pathway of methane production of methanogens (Gill et al. 2006). This finding triggered the potential of modulating the growth dynamics of Methanobrevibacter smithii, the major representative of the human colonic methanogens, as a potential target to reduce energy harvest in obese individuals (Samuel et al. 2007; Schwiertz et al. 2010).

Prebiotics are defined as "nondigestible food ingredient that beneficially affects the host by selectively stimulating the growth and/or activity of one or a limited number of bacteria in the colon, and thus improving host health" (Gibson and Roberfroid 1995). Prebiotic treatment offers a wide range of benefits. It does not only promote the growth of specific bacteria but also inhibits the growth of certain other groups. Such effect was observed for instance by Everard et al. (2011) in ob/ob mice after prebiotic treatment. The extensive gut microbiota analysis identified a catalog of more than 100 operational taxonomic units (OTUs) that were different after the administration of the prebiotic feeding. Furthermore, fold changes (increase/decrease) of certain bacteria of more than tenfold were observed in some cases.

The administration of prebiotics also stimulates the production of SCFA which may modulate the secretion of gut peptides (Brown et al. 2003; Ge et al. 2008; Samuel et al. 2008; Kimura et al. 2011). Prebiotics may exert a satietogenic effect as demonstrated and confirmed in studies with mice in which the effects of acetate on production of appetite suppression were shown, even in absence of increased levels of GLP-1 and PYY (Frost et al. 2014). In humans, the satietogenic effects of prebiotics such as oligofructose have also been shown (Cani et al. 2006, 2009a).

Some data suggest that prebiotics also have the potential of enhancing the gut barrier which consequently improves metabolic disorders (Clarke et al. 2012). Cani et al. (2009b) observed that prebiotic (oligofructose) consumption in mice stimulated the production of GLP-2 which, at the same time, may lower plasma LPS, enhancing mucosal barrier function by improving tight junctions. As described by the authors, a wide range of specific tight junction proteins controls gut permeability. ZO-1 and occludin proteins, in particular, have been considered as key markers of tight junction integrity. In this study, it was observed that treatment with prebiotics increased the mRNA levels of these proteins in the jejunum segment. Furthermore, oligofructose also stimulated the growth of Bifidobacterium spp which was also linked to a reduction in gut permeability. In addition, an increased production of SCFA is thought to be characteristic of the obese microbiome and it has been paradoxically observed to be reversed with the use of prebiotics (Salazar et al. 2014).

The mechanisms through which prebiotics act have been suggested to be dose dependent (Parnell and Reimer 2012). Therefore, the full assessment of the therapeutic potential of prebiotics for treating obesity needs further study. 


\section{Diet}

A high diverse microbiota is believed to be more resistant to changes when compared to less diverse communities (Ursell et al. 2013). As explained by Alcock et al. (2014), the competing groups from a diverse microbiota may invest resources in counteracting and cooperating with each rather than manipulating the host.

Diet in general has been shown to exert an important impact on the gut microbiota regardless of other variables such as sanitation, ethnicity and climate (Chen et al. 2014). For instance, a study comparing the composition of the microbiota from omnivores, carnivores and herbivores (in mammalian species and humans) revealed a separation of carnivores and omnivores from herbivores (Muegge et al. 2011). The authors emphasized the relevance of diet in establishing this differentiation among the analyzed communities. Another study correlated a long-term diet with gut microbial enterotypes (Wu et al. 2011). The enterotype concept consists of clustering the gut bacterial community in three different consortia: Bacteroides-, Prevotella- or Ruminococcus-enriched, respectively. Bacteroides enterotype has been found in subjects with a diet rich in animal fat, protein and saturated fats, whereas a diet low in these dietary components but rich in carbohydrates and simple sugars has been associated with the Prevotella enterotype (Wu et al. 2011).

Therefore, it is of great interest to identify certain dietary compounds for the re-establishment of the disturbed balance of the microbiota from obese subjects as a potential alternative to treat obesity. So far, these dietary compounds have been restricted to carbohydrates. For instance, the study from Yang et al. (2013) suggests that the fermentation of certain cereal grains may be beneficial in improving health from obese individuals. The authors found small differences in propionate and butyrate production in the microbiota activity from obese subjects when compared to lean after the in vitro fermentation with different dietary fibers. However, health improvement was suggested to depend not on the total cumulative SCFA production but on the final SCFA ratios produced after fermentation. In addition, the assessment of fibers of different apple cultivars in an in vitro fermentation using microbiota from diet-induced obese mice by Condezo-Hoyos et al. (2014) suggests that such compounds may help to stabilize disturbed microbiota in obese subjects. Furthermore, the normalization of the endocannabinoid (eCB) system has been shown to be achieved by prebiotic treatment. Muccioli et al. (2010) found a consistent decrease in colonic $\mathrm{CB}_{1}$ and plasma LPS levels in $o b /$ $o b$ mice fed with prebiotics (mixture of oligofructose). The authors suggest that the manipulation of gut microbiota composition using prebiotics potentially decreases the development of fat mass and gut permeability in obese mice.
However, dietary interventions in humans show that there is a very strong individual variation in responses (Korpela et al. 2014; Salonen et al. 2014). Salonen et al. (2014) attributed only $10 \%$ of the changes in the microbiota composition to diet after the study of obese subjects following four different fully controlled diets in a weight loss program. As mentioned earlier, approximately $57 \%$ of changes in the composition of the microbiota have been attributed to diet. However, this has been observed in studies with mice. As explained by Salonen et al. (2014), the differences in their outcome and such reference value could be attributed to the fact that there is smaller total variance in the mice microbiota due to a better control of environmental and genetic variables in these animals. Therefore, it was suggested to stratify human individuals into responders and nonresponders based on their gut microbiota as previously suggested with considering fecal microbial transplantations.

Another factor to consider is that highly targeted specific approaches can potentially affect the diversity of the gut microbial community and promote a dysbalance. For instance, the findings from Salonen et al. (2014) provide an indication that a specific prebiotic may elicit the highly targeted dominance of certain groups, affecting the natural balance. Therefore, the promotion of a diverse community is suggested to be accomplished by providing complex or multiple substrates (Salonen et al. 2014).

Compared to animal data, the data from human dietary interventions are less conclusive, which could be due to the fact that the high degree of variation in individuals makes it hard to find a "normal" response or normal/healthy microbiota composition for that matter. This represents considerable frustration in nutritional studies which bears two questions: (i) is there any strategy that could be applied to understand better this individuality? and (ii) since variation has been considered a standard noise, can it really be handled or does it preclude to identify any effect on the microbiota composition? Furthermore, an important aspect to consider in dietary studies is the choice of its design which will make a major impact on finding statistically differences in the data.

\section{Can we predict dietary response based on microbiota composition?}

The vast inter-individual variation in terms of composition and functional properties of the microbiota of healthy human individuals makes responses to dietary interventions difficult to predict and highly variable (Korpela et al. 2014). However, the proposed niche specialization formed by a metabolic network between different bacteria capable of a specific enzymatic transformation (Arumugam et al. 
2011; Wu et al. 2011; Faust et al. 2012; Lozupone et al. 2012; Lampe et al. 2013) could be used, together with the "-omics" platform (meta-genomics, meta-transcriptomics, meta-proteomics and metabolomics), as an approach to predict the response of gut microbiota to certain perturbations in the ecosystem.

The concept of nutritional phenotype was introduced by Zeisel et al. (2005) which has been proposed as a tool that quantitatively indicates the paths by which environment and genes influence human health integrating diet as a primary factor. The inclusion of epigenetic, genetic, gut microbiome and metabolomics data has been suggested in order to create multi-dimensional data which can be used for the characterization of health in individuals (Lampe et al. 2013), or as a means of stratifying individuals into potential responders/nonresponders.

Furthermore, as mentioned before, synthetic human gut microbial communities selected from specific collections of members of the microbiota may help to represent certain physiological or pathological states, from which functions could be distilled for making in silico predictions attributed exclusively to the gut microbiota (Faith et al. 2010). Such model communities may help to elucidate (in silico) the modulation of gene expression by microbiota in response to changes that include host physiological status, diet or colonization by other microorganism (Faith et al. 2010).

Research is growing in this area. For instance, Faith et al. (2011) and McNulty et al. (2013) have recently used gnotobiotic mice to shape personalized culture collections (ranging from 10 to 12 species) and manipulate them to allow extensively studying of the effects of defined dietary perturbations (high in fat, simple sugars, polysaccharides or protein) on the species abundance and gene expression. However, when considering humans and all the complexity found in the gut bacterial community as a whole, a challenge of modulating the gut microbiota with therapeutic purposes implies the identification of individuals that respond positively to the intervention (Korpela et al. 2014). For instance, Korpela et al. (2014) studied three independent data sets of studies including obese individuals following different dietary interventions. The authors found that some individuals respond to treatment while others do not respond or show adverse responses.

As also proposed with personalized dietary recommendations, the prediction of a dietary response based on the microbiota requires the consideration of different factors (Lampe et al. 2013):

(i) A consensus about the inclusion data considered for this kind of analysis, in particular, the application of biostatistical approaches;

(ii) An evaluation of the most effective way to integrate omics data; (iii) The use of dietary intervention studies with the aim of generating a phenotypic profile. In this regard, randomized crossover designed control feeding studies have been suggested as powerful tools in which the -omics platform can be validated and tested for their robustness with the purpose of deeply characterizing the effects of diet and the response in human beings.

Furthermore, (iv) the assumption that the metabolic structure is uniform among individuals has to be overcome and, therefore, the belief that there is a direct cause-effect relationship;

Finally, an important factor to consider is (v) the lack of a robust healthy phenotype from which dietary recommendations can be developed.

\section{Concluding remarks}

The manipulation of gut microbiota represents a potential tool to treat obesity which can be used as an argument to debate Charles Dickens words: "Subdue your appetites, my dears, and you've conquered human nature." However, gut microbiota manipulation is not a substitute for exercise and healthy diet (Moreno-Indias et al. 2014). Furthermore, before any strategy aimed to modulate the human gut microbiota in order to prevent or tackle obesity is used, it demands vast amounts of evidence and hence, inevitably, further research.

Acknowledgments This study was partly funded by the Top Institute Food and Nutrition (GH004) (TIFN, Wageningen, The Netherlands).

Conflict of interest Authors Marisol Aguirre and Koen Venema declare that they have no conflict of interest.

\section{References}

Aguirre M, Jonkers DM, Troost FJ, Roeselers G, Venema K (2014) In vitro characterization of the impact of different substrates on metabolite production, energy extraction and composition of gut microbiota from lean and obese subjects. PLoS ONE 9:e113864

Alcock J, Maley CC, Aktipis CA (2014) Is eating behavior manipulated by the gastrointestinal microbiota? Evolutionary pressures and potential mechanisms. BioEssays 36:940-949

Allen-Vercoe E, Reid G, Viner N, Gloor GB, Hota S, Kim P, Lee C, O'Doherty K, Vanner SJ, Weese JS, Petrof EO (2012) A Canadian Working Group report on fecal microbial therapy: microbial ecosystems therapeutics. Can J Gastroenterol 26:457-462

An HM, Park SY, Lee do K, Kim JR, Cha MK, Lee SW, Lim HT, Kim KJ, Ha NJ (2011) Antiobesity and lipid-lowering effects of Bifidobacterium spp. in high fat diet-induced obese rats. Lipids Health Dis 10:116

Angelakis E, Merhej V, Raoult D (2013) Related actions of probiotics and antibiotics on gut microbiota and weight modification. Lancet Infect Dis 13:889-899 
Armougom F, Henry M, Vialettes B, Raccah D, Raoult D (2009) Monitoring bacterial community of human gut microbiota reveals an increase in Lactobacillus in obese patients and Methanogens in anorexic patients. PLoS ONE 4:e7125

Arora T, Anastasovska J, Gibson G, Tuohy K, Sharma RK, Bell J, Frost G (2012) Effect of Lactobacillus acidophilus NCDC 13 supplementation on the progression of obesity in diet-induced obese mice. Br J Nutr 108:1382-1389

Arumugam M, Raes J, Pelletier E, Le Paslier D, Yamada T, Mende DR, Fernandes GR, Tap J, Bruls T, Batto JM, Bertalan M, Borruel N, Casellas F, Fernandez L, Gautier L, Hansen T, Hattori M, Hayashi T, Kleerebezem M, Kurokawa K, Leclerc M, Levenez F, Manichanh C, Nielsen HB, Nielsen T, Pons N, Poulain J, Qin J, Sicheritz-Ponten T, Tims S, Torrents D, Ugarte E, Zoetendal EG, Wang J, Guarner F, Pedersen O, de Vos WM, Brunak S, Dore J, Meta HITC, Antolin M, Artiguenave F, Blottiere HM, Almeida M, Brechot C, Cara C, Chervaux C, Cultrone A, Delorme C, Denariaz G, Dervyn R, Foerstner KU, Friss C, van de Guchte M, Guedon E, Haimet F, Huber W, van Hylckama-Vlieg J, Jamet A, Juste C, Kaci G, Knol J, Lakhdari O, Layec S, Le Roux K, Maguin E, Merieux A, Melo Minardi R, M'Rini C, Muller J, Oozeer R, Parkhill J, Renault P, Rescigno M, Sanchez N, Sunagawa S, Torrejon A, Turner K, Vandemeulebrouck G, Varela E, Winogradsky Y, Zeller G, Weissenbach J, Ehrlich SD, Bork P (2011) Enterotypes of the human gut microbiome. Nature 473:174-180

Backhed F, Ding H, Wang T, Hooper LV, Koh GY, Nagy A, Semenkovich CF, Gordon JI (2004) The gut microbiota as an environmental factor that regulates fat storage. Proc Natl Acad Sci USA 101:15718-15723

Bailey LC, Forrest CB, Zhang P, Richards TM, Livshits A, DeRusso PA (2014) Association of antibiotics in infancy with early childhood obesity. JAMA Pediatr 168:1063-1069

Bakken JS (2009) Fecal bacteriotherapy for recurrent Clostridium difficile infection. Anaerobe 15:285-289

Bartosch S, Fite A, Macfarlane GT, McMurdo ME (2004) Characterization of bacterial communities in feces from healthy elderly volunteers and hospitalized elderly patients by using real-time PCR and effects of antibiotic treatment on the fecal microbiota. Appl Environ Microbiol 70:3575-3581

Bech-Nielsen GV, Hansen CH, Hufeldt MR, Nielsen DS, Aasted B, Vogensen FK, Midtvedt T, Hansen AK (2012) Manipulation of the gut microbiota in C57BL/6 mice changes glucose tolerance without affecting weight development and gut mucosal immunity. Res Vet Sci 92:501-508

Bifulco M (2014) Antibiotics exposure in obesity: an update of a complex relationship. Endocrine 48(1):12-13

Borody TJ, George L, Andrews P, Brandl S, Noonan S, Cole P, Hyland L, Morgan A, Maysey J, Moore-Jones D (1989) Bowelflora alteration: a potential cure for inflammatory bowel disease and irritable bowel syndrome? Med J Aust 150:604

Borody TJ, Warren EF, Leis SM, Surace R, Ashman O, Siarakas S (2004) Bacteriotherapy using fecal flora: toying with human motions. J Clin Gastroenterol 38:475-483

Borody TJ, Brandt LJ, Paramsothy S (2014) Therapeutic faecal microbiota transplantation: current status and future developments. Curr Opin Gastroenterol 30:97-105

Brown AJ, Goldsworthy SM, Barnes AA, Eilert MM, Tcheang L, Daniels D, Muir AI, Wigglesworth MJ, Kinghorn I, Fraser NJ, Pike NB, Strum JC, Steplewski KM, Murdock PR, Holder JC, Marshall FH, Szekeres PG, Wilson S, Ignar DM, Foord SM, Wise A, Dowell SJ (2003) The Orphan G protein-coupled receptors GPR41 and GPR43 are activated by propionate and other short chain carboxylic acids. J Biol Chem 278:11312-11319

Brugman S, Klatter FA, Visser JT, Wildeboer-Veloo AC, Harmsen HJ, Rozing J, Bos NA (2006) Antibiotic treatment partially protects against type 1 diabetes in the Bio-Breeding diabetesprone rat. Is the gut flora involved in the development of type 1 diabetes? Diabetologia 49:2105-2108

Butaye P, Devriese LA, Haesebrouck F (2003) Antimicrobial growth promoters used in animal feed: effects of less well known antibiotics on gram-positive bacteria. Clin Microbiol Rev $16: 175-188$

Cani PD, Dewever C, Delzenne NM (2004) Inulin-type fructans modulate gastrointestinal peptides involved in appetite regulation (glucagon-like peptide-1 and ghrelin) in rats. Br J Nutr 92:521-526

Cani PD, Daubioul CA, Reusens B, Remacle C, Catillon G, Delzenne NM (2005) Involvement of endogenous glucagon-like peptide1(7-36) amide on glycaemia-lowering effect of oligofructose in streptozotocin-treated rats. J Endocrinol 185:457-465

Cani PD, Joly E, Horsmans Y, Delzenne NM (2006) Oligofructose promotes satiety in healthy human: a pilot study. Eur J Clin Nutr 60:567-572

Cani PD, Bibiloni R, Knauf C, Waget A, Neyrinck AM, Delzenne NM, Burcelin R (2008) Changes in gut microbiota control metabolic endotoxemia-induced inflammation in high-fat dietinduced obesity and diabetes in mice. Diabetes 57:1470-1481

Cani PD, Lecourt E, Dewulf EM, Sohet FM, Pachikian BD, Naslain D, De Backer F, Neyrinck AM, Delzenne NM (2009a) Gut microbiota fermentation of prebiotics increases satietogenic and incretin gut peptide production with consequences for appetite sensation and glucose response after a meal. Am J Clin Nutr 90:1236-1243

Cani PD, Possemiers S, Van de Wiele T, Guiot Y, Everard A, Rottier O, Geurts L, Naslain D, Neyrinck A, Lambert DM, Muccioli GG, Delzenne NM (2009b) Changes in gut microbiota control inflammation in obese mice through a mechanism involving GLP-2-driven improvement of gut permeability. Gut 58:1091-1103

Chen JJ, Wang R, Li XF, Wang RL (2011) Bifidobacterium longum supplementation improved high-fat-fed-induced metabolic syndrome and promoted intestinal Reg I gene expression. Exp Biol Med (Maywood) 236:823-831

Chen J, Wang R, Li XF, Wang RL (2012) Bifidobacterium adolescentis supplementation ameliorates visceral fat accumulation and insulin sensitivity in an experimental model of the metabolic syndrome. Br J Nutr 107:1429-1434

Chen J, He X, Huang J (2014) Diet effects in gut microbiome and obesity. J Food Sci 79:R442-R451

Cho I, Yamanishi S, Cox L, Methe BA, Zavadil J, Li K, Gao Z, Mahana D, Raju K, Teitler I, Li H, Alekseyenko AV, Blaser MJ (2012) Antibiotics in early life alter the murine colonic microbiome and adiposity. Nature 488:621-626

Chua SC Jr, White DW, Wu-Peng XS, Liu SM, Okada N, Kershaw EE, Chung WK, Power-Kehoe L, Chua M, Tartaglia LA, Leibel RL (1996) Phenotype of fatty due to Gln269Pro mutation in the leptin receptor (Lepr). Diabetes 45:1141-1143

Clarke SF, Murphy EF, Nilaweera K, Ross PR, Shanahan F, O'Toole PW, Cotter PD (2012) The gut microbiota and its relationship to diet and obesity: new insights. Gut Microbes 3:186-202

Condezo-Hoyos L, Mohanty IP, Noratto GD (2014) Assessing nondigestible compounds in apple cultivars and their potential as modulators of obese faecal microbiota in vitro. Food Chem 161:208-215

de La Serre CB, Ellis CL, Lee J, Hartman AL, Rutledge JC, Raybould HE (2010) Propensity to high-fat diet-induced obesity in rats is associated with changes in the gut microbiota and gut inflammation. Am J Physiol Gastrointest Liver Physiol 299:G440 G448

Delzenne N, Reid G (2009) No causal link between obesity and probiotics. Nat Rev Microbiol 7:901; author reply 901 
Delzenne NM, Cani PD, Daubioul C, Neyrinck AM (2005) Impact of inulin and oligofructose on gastrointestinal peptides. Br J Nutr 93(Suppl 1):S157-S161

Dessein R, Gironella M, Vignal C, Peyrin-Biroulet L, Sokol H, Secher T, Lacas-Gervais S, Gratadoux JJ, Lafont F, Dagorn JC, Ryffel B, Akira S, Langella P, Nunez G, Sirard JC, Iovanna J, Simonet M, Chamaillard M (2009) Toll-like receptor 2 is critical for induction of Reg 3 beta expression and intestinal clearance of Yersinia pseudotuberculosis. Gut 58:771-776

Dethlefsen L, Relman DA (2011) Incomplete recovery and individualized responses of the human distal gut microbiota to repeated antibiotic perturbation. Proc Natl Acad Sci USA 108(Suppl 1):4554-4561

Dethlefsen L, Huse S, Sogin ML, Relman DA (2008) The pervasive effects of an antibiotic on the human gut microbiota, as revealed by deep 16S rRNA sequencing. PLoS Biol 6:e280

Dibner JJ, Richards JD (2005) Antibiotic growth promoters in agriculture: history and mode of action. Poult Sci 84:634-643

Druart Cl, Alligier M, Salazar N, Neyrinck AM, Delzenne NM (2014) Modulation of the gut microbiota by nutrients with prebiotic and probiotic properties. Adv Nutr Int Rev J 5:624S-633S

Ehrlich SD (2009) Probiotics-little evidence for a link to obesity. Nat Rev Microbiol 7:901; author reply 901

El-Matary W, Simpson R, Ricketts-Burns N (2012) Fecal microbiota transplantation: are we opening a can of worms? Gastroenterology 143:e19

Everard A, Lazarevic V, Derrien M, Girard M, Muccioli GG, Neyrinck AM, Possemiers S, Van Holle A, Francois P, de Vos WM, Delzenne NM, Schrenzel J, Cani PD (2011) Responses of gut microbiota and glucose and lipid metabolism to prebiotics in genetic obese and diet-induced leptin-resistant mice. Diabetes 60:2775-2786

Everard A, Belzer C, Geurts L, Ouwerkerk JP, Druart C, Bindels LB, Guiot Y, Derrien M, Muccioli GG, Delzenne NM, de Vos WM, Cani PD (2013) Cross-talk between Akkermansia muciniphila and intestinal epithelium controls diet-induced obesity. Proc Natl Acad Sci USA 110:9066-9071

Faith JJ, Rey FE, O’Donnell D, Karlsson M, McNulty NP, Kallstrom G, Goodman AL, Gordon JI (2010) Creating and characterizing communities of human gut microbes in gnotobiotic mice. ISME J 4:1094-1098

Faith JJ, McNulty NP, Rey FE, Gordon JI (2011) Predicting a human gut microbiota's response to diet in gnotobiotic mice. Science 333:101-104

Faith JJ, Ahern PP, Ridaura VK, Cheng J, Gordon JI (2014) Identifying gut microbe-host phenotype relationships using combinatorial communities in gnotobiotic mice. Sci Transl Med 6:220ra211

Falagas ME, Karageorgopoulos DE (2010) Adjustment of dosing of antimicrobial agents for bodyweight in adults. Lancet 375:248-251

Faust K, Sathirapongsasuti JF, Izard J, Segata N, Gevers D, Raes J, Huttenhower C (2012) Microbial co-occurrence relationships in the human microbiome. PLoS Comput Biol 8:e1002606

Fava F, Gitau R, Griffin BA, Gibson GR, Tuohy KM, Lovegrove JA (2013) The type and quantity of dietary fat and carbohydrate alter faecal microbiome and short-chain fatty acid excretion in a metabolic syndrome 'at-risk' population. Int J Obes (Lond) 37:216-223

Feighner SD, Dashkevicz MP (1987) Subtherapeutic levels of antibiotics in poultry feeds and their effects on weight gain, feed efficiency, and bacterial cholyltaurine hydrolase activity. Appl Environ Microbiol 53:331-336

Fouhy F, Guinane CM, Hussey S, Wall R, Ryan CA, Dempsey EM, Murphy B, Ross RP, Fitzgerald GF, Stanton C, Cotter PD (2012) High-throughput sequencing reveals the incomplete, short-term recovery of infant gut microbiota following parenteral antibiotic treatment with ampicillin and gentamicin. Antimicrob Agents Chemother 56:5811-5820

Frost G, Sleeth ML, Sahuri-Arisoylu M, Lizarbe B, Cerdan S, Brody L, Anastasovska J, Ghourab S, Hankir M, Zhang S, Carling D, Swann JR, Gibson G, Viardot A, Morrison D, Louise Thomas E, Bell JD (2014) The short-chain fatty acid acetate reduces appetite via a central homeostatic mechanism. Nat Commun 5:3611

Ge H, Li X, Weiszmann J, Wang P, Baribault H, Chen JL, Tian H, Li Y (2008) Activation of $G$ protein-coupled receptor 43 in adipocytes leads to inhibition of lipolysis and suppression of plasma free fatty acids. Endocrinology 149:4519-4526

Gibson GR, Roberfroid MB (1995) Dietary modulation of the human colonic microbiota: introducing the concept of prebiotics. J Nutr 125:1401-1412

Gill SR, Pop M, Deboy RT, Eckburg PB, Turnbaugh PJ, Samuel BS, Gordon JI, Relman DA, Fraser-Liggett CM, Nelson KE (2006) Metagenomic analysis of the human distal gut microbiome. Science 312:1355-1359

Gough E, Shaikh H, Manges AR (2011) Systematic review of intestinal microbiota transplantation (fecal bacteriotherapy) for recurrent Clostridium difficile infection. Clin Infect Dis 53:994-1002

Guida S, Venema K (2015) Gut microbiota and obesity: involvement of the adipose tissue. J Funct Foods 14:407-423

Hamad EM, Sato M, Uzu K, Yoshida T, Higashi S, Kawakami H, Kadooka Y, Matsuyama H, Abd El-Gawad IA, Imaizumi K (2009) Milk fermented by Lactobacillus gasseri SBT2055 influences adipocyte size via inhibition of dietary fat absorption in Zucker rats. Br J Nutr 101:716-724

Harris K, Kassis A, Major G, Chou CJ (2012) Is the gut microbiota a new factor contributing to obesity and its metabolic disorders? J Obes 2012:879151

Hernandez E, Bargiela R, Diez MS, Friedrichs A, Perez-Cobas AE, Gosalbes MJ, Knecht H, Martinez-Martinez M, Seifert J, von Bergen M, Artacho A, Ruiz A, Campoy C, Latorre A, Ott SJ, Moya A, Suarez A, Martins dos Santos VA, Ferrer M (2013) Functional consequences of microbial shifts in the human gastrointestinal tract linked to antibiotic treatment and obesity. Gut Microbes 4:306-315

Hotamisligil GS (2006) Inflammation and metabolic disorders. Nature 444:860-867

Ilmonen J, Isolauri E, Poussa T, Laitinen K (2011) Impact of dietary counselling and probiotic intervention on maternal anthropometric measurements during and after pregnancy: a randomized placebo-controlled trial. Clin Nutr 30:156-164

Ivanov II, Atarashi K, Manel N, Brodie EL, Shima T, Karaoz U, Wei D, Goldfarb KC, Santee CA, Lynch SV, Tanoue T, Imaoka A, Itoh K, Takeda K, Umesaki Y, Honda K, Littman DR (2009) Induction of intestinal Th17 cells by segmented filamentous bacteria. Cell 139:485-498

Jernberg C, Lofmark S, Edlund C, Jansson JK (2010) Long-term impacts of antibiotic exposure on the human intestinal microbiota. Microbiology 156:3216-3223

Jess T (2014) Microbiota, antibiotics, and obesity. N Engl J Med 371:2526-2528

Kadooka Y, Sato M, Imaizumi K, Ogawa A, Ikuyama K, Akai Y, Okano M, Kagoshima M, Tsuchida T (2010) Regulation of abdominal adiposity by probiotics (Lactobacillus gasseri SBT2055) in adults with obese tendencies in a randomized controlled trial. Eur J Clin Nutr 64:636-643

Kang JH, Yun SI, Park HO (2010) Effects of Lactobacillus gasseri BNR17 on body weight and adipose tissue mass in diet-induced overweight rats. J Microbiol 48:712-714

Kang JH, Yun SI, Park MH, Park JH, Jeong SY, Park HO (2013) Anti-obesity effect of Lactobacillus gasseri BNR17 in highsucrose diet-induced obese mice. PLoS ONE 8:e54617 
Kerac M, Bunn J, Seal A, Thindwa M, Tomkins A, Sadler K, Bahwere P, Collins S (2009) Probiotics and prebiotics for severe acute malnutrition (PRONUT study): a double-blind efficacy randomised controlled trial in Malawi. Lancet 374:136-144

Kimura I, Inoue D, Maeda T, Hara T, Ichimura A, Miyauchi S, Kobayashi M, Hirasawa A, Tsujimoto G (2011) Short-chain fatty acids and ketones directly regulate sympathetic nervous system via G protein-coupled receptor 41 (GPR41). Proc Natl Acad Sci USA 108:8030-8035

Klaenhammer TR, Altermann E, Pfeiler E, Buck BL, Goh YJ, O'Flaherty S, Barrangou R, Duong T (2008) Functional genomics of probiotic Lactobacilli. J Clin Gastroenterol 42(Suppl 3 Pt 2):S160-S162

Korpela K, Flint HJ, Johnstone AM, Lappi J, Poutanen K, Dewulf E, Delzenne N, de Vos WM, Salonen A (2014) Gut microbiota signatures predict host and microbiota responses to dietary interventions in obese individuals. PLoS ONE 9:e90702

Lampe JW, Navarro SL, Hullar MA, Shojaie A (2013) Interindividual differences in response to dietary intervention: integrating omics platforms towards personalised dietary recommendations. Proc Nutr Soc 72:207-218

Leber B, Tripolt NJ, Blattl D, Eder M, Wascher TC, Pieber TR, Stauber R, Sourij H, Oettl K, Stadlbauer V (2012) The influence of probiotic supplementation on gut permeability in patients with metabolic syndrome: an open label, randomized pilot study. Eur J Clin Nutr 66:1110-1115

Lozupone C, Faust K, Raes J, Faith JJ, Frank DN, Zaneveld J, Gordon JI, Knight R (2012) Identifying genomic and metabolic features that can underlie early successional and opportunistic lifestyles of human gut symbionts. Genome Res 22:1974-1984

Luoto R, Kalliomaki M, Laitinen K, Isolauri E (2010) The impact of perinatal probiotic intervention on the development of overweight and obesity: follow-up study from birth to 10 years. Int $\mathrm{J}$ Obes (Lond) 34:1531-1537

McNulty NP, Wu M, Erickson AR, Pan C, Erickson BK, Martens EC, Pudlo NA, Muegge BD, Henrissat B, Hettich RL, Gordon JI (2013) Effects of diet on resource utilization by a model human gut microbiota containing Bacteroides cellulosilyticus $\mathrm{WH} 2$, a symbiont with an extensive glycobiome. PLoS Biol 11:e1001637

Membrez M, Blancher F, Jaquet M, Bibiloni R, Cani PD, Burcelin RG, Corthesy I, Mace K, Chou CJ (2008) Gut microbiota modulation with norfloxacin and ampicillin enhances glucose tolerance in mice. FASEB J 22:2416-2426

Million M, Maraninchi M, Henry M, Armougom F, Richet H, Carrieri P, Valero R, Raccah D, Vialettes B, Raoult D (2012) Obesityassociated gut microbiota is enriched in Lactobacillus reuteri and depleted in Bifidobacterium animalis and Methanobrevibacter smithii. Int J Obes (Lond) 36:817-825

Morelli L, Capurso L (2012) FAO/WHO guidelines on probiotics: 10 years later. J Clin Gastroenterol 46(Suppl):S1-S2

Moreno-Indias I, Cardona F, Tinahones FJ, Queipo-Ortuno MI (2014) Impact of the gut microbiota on the development of obesity and type 2 diabetes mellitus. Front Microbiol 5:190

Muccioli GG, Naslain D, Backhed F, Reigstad CS, Lambert DM, Delzenne NM, Cani PD (2010) The endocannabinoid system links gut microbiota to adipogenesis. Mol Syst Biol 6:392

Muegge BD, Kuczynski J, Knights D, Clemente JC, Gonzalez A, Fontana L, Henrissat B, Knight R, Gordon JI (2011) Diet drives convergence in gut microbiome functions across mammalian phylogeny and within humans. Science 332:970-974

Nicholson JK, Holmes E, Wilson ID (2005) Gut microorganisms, mammalian metabolism and personalized health care. Nat Rev Microbiol 3:431-438

Nieuwdorp M, Gilijamse PW, Pai N, Kaplan LM (2014) Role of the microbiome in energy regulation and metabolism. Gastroenterology 146:1525-1533
Pai MP, Bearden DT (2007) Antimicrobial dosing considerations in obese adult patients. Pharmacotherapy 27:1081-1091

Parnell JA, Reimer RA (2012) Prebiotic fibres dose-dependently increase satiety hormones and alter Bacteroidetes and Firmicutes in lean and obese JCR:LA-cp rats. Br J Nutr 107:601-613

Perez-Cobas AE, Gosalbes MJ, Friedrichs A, Knecht H, Artacho A, Eismann K, Otto W, Rojo D, Bargiela R, von Bergen M, Neulinger SC, Daumer C, Heinsen FA, Latorre A, Barbas C, Seifert J, dos Santos VM, Ott SJ, Ferrer M, Moya A (2013) Gut microbiota disturbance during antibiotic therapy: a multi-omic approach. Gut 62:1591-1601

Petrof EO, Claud EC, Gloor GB, Allen-Vercoe E (2013a) Microbial ecosystems therapeutics: a new paradigm in medicine? Benef Microbes 4:53-65

Petrof EO, Gloor GB, Vanner SJ, Weese SJ, Carter D, Daigneault MC, Brown EM, Schroeter K, Allen-Vercoe E (2013b) Stool substitute transplant therapy for the eradication of Clostridium difficile infection: 'RePOOPulating' the gut. Microbiome 1:3

Polotsky HN, Polotsky AJ (2010) One size may not fit all: pondering antibiotic dosing in obesity. Maturitas 66:381-382

Postigo R, Kim JH (2012) Colonoscopic versus nasogastric fecal transplantation for the treatment of Clostridium difficile infection: a review and pooled analysis. Infection 40:643-648

Qin J, Li R, Raes J, Arumugam M, Burgdorf KS, Manichanh C, Nielsen T, Pons N, Levenez F, Yamada T, Mende DR, Li J, Xu J, Li S, Li D, Cao J, Wang B, Liang H, Zheng H, Xie Y, Tap J, Lepage P, Bertalan M, Batto JM, Hansen T, Le Paslier D, Linneberg A, Nielsen HB, Pelletier E, Renault P, SicheritzPonten T, Turner K, Zhu H, Yu C, Jian M, Zhou Y, Li Y, Zhang $\mathrm{X}$, Qin N, Yang H, Wang J, Brunak S, Dore J, Guarner F, Kristiansen K, Pedersen O, Parkhill J, Weissenbach J, Meta HITC, Bork P, Ehrlich SD (2010) A human gut microbial gene catalogue established by metagenomic sequencing. Nature 464:59-65

Ramakrishna BS (2013) Role of the gut microbiota in human nutrition and metabolism. J Gastroenterol Hepatol 28(Suppl 4):9-17

Raoult D (2009) Probiotics and obesity: a link? Nat Rev Microbiol 7:616

Requena T, Cotter P, Shahar DR, Kleiveland CR, Martinez-Cuesta MC, Pelaez C, Lea T (2013) Interactions between gut microbiota, food and the obese host. Trends Food Sci Technol 34:44-53

Robinson CJ, Young VB (2010) Antibiotic administration alters the community structure of the gastrointestinal micobiota. Gut Microbes 1:279-284

Rosenberg IH, Beisel WR, Gordon JE, Katz M, Keusch GT, Luckey TD, Mata LJ (1974) Infant and child enteritis-malabsorptionmalnutrition: the potential of limited studies with low-dose antibiotic feeding. Am J Clin Nutr 27:304-309

Salazar N, Dewulf EM, Neyrinck AM, Bindels LB, Cani PD, Mahillon J, de Vos WM, Thissen JP, Gueimonde M, de Los Reyes-Gavilan CG, Delzenne NM (2014) Inulin-type fructans modulate intestinal Bifidobacterium species populations and decrease fecal short-chain fatty acids in obese women. Clin Nutr 34(3):501-507

Salonen A, Lahti L, Salojarvi J, Holtrop G, Korpela K, Duncan SH, Date P, Farquharson F, Johnstone AM, Lobley GE, Louis P, Flint HJ, de Vos WM (2014) Impact of diet and individual variation on intestinal microbiota composition and fermentation products in obese men. ISME $\mathbf{J}$ 8:2218-2230

Samuel BS, Hansen EE, Manchester JK, Coutinho PM, Henrissat B, Fulton R, Latreille P, Kim K, Wilson RK, Gordon JI (2007) Genomic and metabolic adaptations of Methanobrevibacter smithii to the human gut. Proc Natl Acad Sci USA 104:10643-10648

Samuel BS, Shaito A, Motoike T, Rey FE, Backhed F, Manchester JK, Hammer RE, Williams SC, Crowley J, Yanagisawa M, Gordon JI (2008) Effects of the gut microbiota on host adiposity 
are modulated by the short-chain fatty-acid binding $\mathrm{G}$ proteincoupled receptor, Gpr41. Proc Natl Acad Sci USA 105: $16767-16772$

Savino F, Roana J, Mandras N, Tarasco V, Locatelli E, Tullio V (2011) Faecal microbiota in breast-fed infants after antibiotic therapy. Acta Paediatr 100:75-78

Schwiertz A, Taras D, Schafer K, Beijer S, Bos NA, Donus C, Hardt PD (2010) Microbiota and SCFA in lean and overweight healthy subjects. Obesity (Silver Spring) 18:190-195

Scott KP, Duncan SH, Flint HJ (2008) Dietary fibre and the gut microbiota. Nutr Bull 33:201-211

Silverman MS, Davis I, Pillai DR (2010) Success of self-administered home fecal transplantation for chronic Clostridium difficile infection. Clin Gastroenterol Hepatol 8:471-473

Smits LP, Bouter KE, de Vos WM, Borody TJ, Nieuwdorp M (2013) Therapeutic potential of fecal microbiota transplantation. Gastroenterology 145:946-953

Solis B, Samartin S, Gomez S, Nova E, de la Rosa B, Marcos A (2002) Probiotics as a help in children suffering from malnutrition and diarrhoea. Eur J Clin Nutr 56(Suppl 3):S57-S59

Thuny F, Richet H, Casalta JP, Angelakis E, Habib G, Raoult D (2010) Vancomycin treatment of infective endocarditis is linked with recently acquired obesity. PLoS ONE 5:e9074

Tripolt NJ, Leber B, Blattl D, Eder M, Wonisch W, Scharnagl H, Stojakovic T, Obermayer-Pietsch B, Wascher TC, Pieber TR, Stadlbauer V, Sourij H (2013) Short communication: effect of supplementation with Lactobacillus casei Shirota on insulin sensitivity, beta-cell function, and markers of endothelial function and inflammation in subjects with metabolic syndrome-a pilot study. J Dairy Sci 96:89-95

Ursell LK, Van Treuren W, Metcalf JL, Pirrung M, Gewirtz A, Knight R (2013) Replenishing our defensive microbes. BioEssays 35:810-817

van Nood E, Speelman P, Kuijper EJ, Keller JJ (2009) Struggling with recurrent Clostridium difficile infections: is donor faeces the solution? Euro Surveill 14(34):19316

Vrieze A, Van Nood E, Holleman F, Salojarvi J, Kootte RS, Bartelsman JF, Dallinga-Thie GM, Ackermans MT, Serlie MJ, Oozeer R, Derrien M, Druesne A, Van Hylckama Vlieg JE, Bloks VW, Groen AK, Heilig HG, Zoetendal EG, Stroes ES, de Vos WM, Hoekstra JB, Nieuwdorp M (2012) Transfer of intestinal microbiota from lean donors increases insulin sensitivity in individuals with metabolic syndrome. Gastroenterology 143(913-916):e917

Wells JM, Loonen LM, Karczewski JM (2010) The role of innate signaling in the homeostasis of tolerance and immunity in the intestine. Int J Med Microbiol 300:41-48

Williams NH, Stahly TS, Zimmerman DR (1997) Effect of level of chronic immune system activation on the growth and dietary lysine needs of pigs fed from 6 to $112 \mathrm{~kg}$. J Anim Sci 75:2481-2496

Wlodarska M, Willing B, Keeney KM, Menendez A, Bergstrom KS, Gill N, Russell SL, Vallance BA, Finlay BB (2011) Antibiotic treatment alters the colonic mucus layer and predisposes the host to exacerbated Citrobacter rodentium-induced colitis. Infect Immun 79:1536-1545

Wu GD, Chen J, Hoffmann C, Bittinger K, Chen YY, Keilbaugh SA, Bewtra M, Knights D, Walters WA, Knight R, Sinha R, Gilroy E, Gupta K, Baldassano R, Nessel L, Li H, Bushman FD, Lewis JD (2011) Linking long-term dietary patterns with gut microbial enterotypes. Science 334:105-108

Yang J, Keshavarzian A, Rose DJ (2013) Impact of dietary fiber fermentation from cereal grains on metabolite production by the fecal microbiota from normal weight and obese individuals. J Med Food 16:862-867

Yun SI, Park HO, Kang JH (2009) Effect of Lactobacillus gasseri BNR17 on blood glucose levels and body weight in a mouse model of type 2 diabetes. J Appl Microbiol 107:1681-1686

Zeisel SH, Freake HC, Bauman DE, Bier DM, Burrin DG, German JB, Klein S, Marquis GS, Milner JA, Pelto GH, Rasmussen KM (2005) The nutritional phenotype in the age of metabolomics. J Nutr 135:1613-1616

Zhang C, Zhang M, Wang S, Han R, Cao Y, Hua W, Mao Y, Zhang X, Pang X, Wei C, Zhao G, Chen Y, Zhao L (2010) Interactions between gut microbiota, host genetics and diet relevant to development of metabolic syndromes in mice. ISME J 4:232-241

Zhang F, Luo W, Shi Y, Fan Z, Ji G (2012) Should we standardize the 1,700-year-old fecal microbiota transplantation? Am J Gastroenterol 107:1755; author reply 1755-1756

Zhao L (2013) The gut microbiota and obesity: from correlation to causality. Nat Rev Micro 11:639-647 